\title{
Mechanical Behavior of 3D Crack Growth in Transparent Rock-Like Material Containing Preexisting Flaws under Compression
}

\author{
Hu-Dan Tang, ${ }^{1,2}$ Zhen-De Zhu, ${ }^{1}$ Ming-Li Zhu, ${ }^{3}$ and Heng-Xing Lin ${ }^{4}$ \\ ${ }^{1}$ Key Laboratory of Ministry of Education for Geomechanics and Embankment Engineering, Institute of Safety and \\ Disaster Prevention Engineering, Hohai University, Nanjing, Jiangsu 210098, China \\ ${ }^{2}$ School of Civil Engineering, Henan Polytechnic University, Jiaozuo, Henan 454000, China \\ ${ }^{3}$ School of Energy Science and Engineering, Henan Polytechnic University, Jiaozuo, Henan 454000, China \\ ${ }^{4}$ Water Conservancy Project Planning and Design Departments, Shanghai Investigation Design \& Research Institute Co. Ltd., \\ Shanghai 200434, China \\ Correspondence should be addressed to Hu-Dan Tang; tanghudan@126.com
}

Received 23 September 2015; Accepted 22 November 2015

Academic Editor: Liviu Marsavina

Copyright @ $2015 \mathrm{Hu}$-Dan Tang et al. This is an open access article distributed under the Creative Commons Attribution License, which permits unrestricted use, distribution, and reproduction in any medium, provided the original work is properly cited.

Mechanical behavior of 3D crack propagation and coalescence is investigated in rock-like material under uniaxial compression. A new transparent rock-like material is developed and a series of uniaxial compressive tests on low temperature transparent resin materials with preexisting 3D flaws are performed in laboratory, with changing values of bridge angle $\beta$ (inclination between the inner tips of the two preexisting flaws) of preexisting flaws in specimens. Furthermore, a theoretical peak strength prediction of 3D cracks coalescence is given. The results show that the coalescence modes of the specimens are varying according to different bridge angles. And the theoretical peak strength prediction agrees well with the experimental observation.

\section{Introduction}

Most of the elastic-brittle materials contain different patterns of flaws. In general, the mechanical behavior of brittle materials may be affected by the micromechanical behavior of the defects. The evolution of cracks depends on the properties of cracks such as size, location, orientation, and loading condition. The propagation of cracks plays a vital role in predicting the breakage process of rock specimens [1-12]. As a rule, the fracture surface is perpendicular to the maximum tensile stress direction. The experimental and theoretical research have shown that microcracks developed in different ways, such as tensile cracks, mixture cracks (tensile cracks, and shear cracks), and shear cracks, and became closed, frictional sliding, intergranular propagating, and kink propagating [13-15]. In the crack evolution process of brittle materials containing preexisting flaws, usually two types of crack are observed, which are wing cracks originating from the tips of preexisting flaws and secondary cracks. Wing cracks are usually caused by tension, while secondary cracks may develop due to shear [16]. Wing cracks initiation in rocks is favored with respect to secondary cracks because of lower toughness of the materials in tension than in shear [17-20]. It is mainly expected that crack initiation follows the direction parallel to the maximum compressive load [21]. Many experiments have been conducted to study the crack initiation, propagation path, and eventual coalescence of the preexisting flaws in specimens made of various substance, including natural rocks or rock-like materials under tensile and compressive loadings [4, 22-24].

From the practical point of view, nearly all rock engineering projects involve, to a certain extent, construction of structures in or on rock masses, which contain different types of flaws. As underground excavations progress into deeper and more complex geological environments, the eventual and ultimate limitation in all mining is depth [24]. Excavationinduced macroscale fractures, such as roof fall, side wall slab, and rock burst [25-29], occur extensively in the side walls 
of underground working face. Understanding of the failure modes around cavities in brittle rocks under compressive loading conditions becomes more and more important in searching solutions to the problem that engineering meets.

Fracture propagation leading to rock failure is a very important topic in rock mechanics research. A number of studies have been done on two-dimensional models plate with preexisting flaws. Crack initiation, propagation, and coalescence have been subjects of intensive investigation in rock mechanics, both theoretically and experimentally. The first theoretical study on the growth of preexisting twodimensional flaws was put forward by Griffith $[30,31]$. Griffith [30] further introduced the concept of critical energy release rate and the crack tip stress intensity factor $(K)$. Relating to the field of rock mechanics, many experimental studies have been conducted to investigate the crack initiation, propagation, and interaction [1-12, 32, 33]. A number of studies have been done on two-dimensional (2D) model plates with throughgoing preexisting fractures, but as is known rock masses contain some finite size of flaws (threedimensional (3D) flaws) existing inside or on the surface of rock materials. In terms of rock experiments, due to the nontransparency of rock material, it is difficult to trace the initiation, propagation, and interaction of fractures within the rock. That is to say, the crack growth analyses based on $2 \mathrm{D}$ model may not truly reflect the real failure properties. Then some studies have been done on 3D specimens [5, 34-46]. In reality, preexisting fractures are $3 \mathrm{D}$ in nature.

Recently, several experiments according 3D crack evolution have been investigated at the Rock Mechanics Laboratory at Hong Kong Polytechnic University. Samples that were prepared in the experiments included a variety of real rocks, PMMA, cement, gypsum, and resin samples. All samples contained a preexisting flaw [40-44]. According to these experiments, both wink cracks and petal cracks initiated from preexisting flaw tips of PMMA and marble samples, and shelllike cracks emerged from the flaw tips of the two materials referred to above sometimes. At the same time, antiwing cracks (opposite to the wing cracks) were induced from the tips of preexisting flaw at a certain distance in compressive stress zone in gabbros specimens $[42,43]$. Liu et al. conducted a series of experimental tests to study $3 \mathrm{D}$ cracks propagation progress of a single surface flaw under the conditions of biaxial compression [44], and a 3D acoustic emission (AE) location system was used $[42,44]$.

However, most of previous studies were focused on the mechanisms and experiments of crack initiation, propagation, and interaction according to $2 \mathrm{D}$ cracks. Although some of significant results have been achieved, there were some deviations between the research results and the truth due to the nature of the material itself, the mechanisms of propagation and coalescence of 3D internal flaws are still not clear until now, and no existing theoretical explanation of $3 \mathrm{D}$ crack evolution was given.

Therefore, we attempt here to give a more refined study on the pattern of $3 \mathrm{D}$ crack initiation, propagation, and coalescence of transparent materials like rocks. On the basis of previous studies, the modeling material used in the paper is improved by being randomly embedded inside transparent

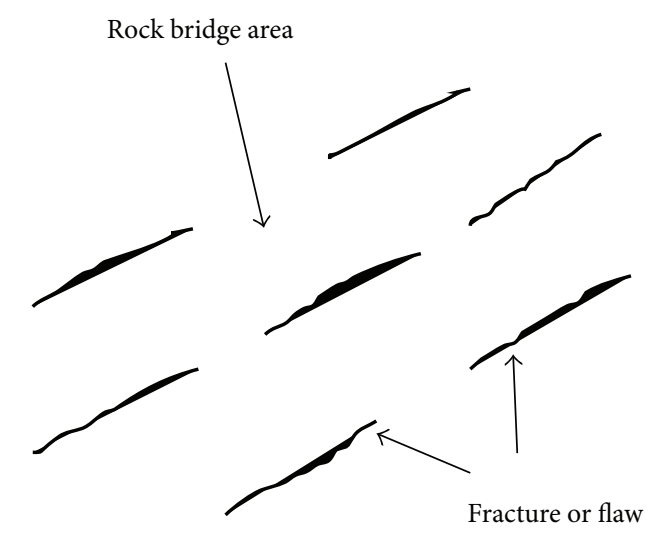

FIGURE 1: Rock bridge area in discontinuous rock.

resin material, certain aggregates of different sizes, and then heterogeneous transparent materials are obtained and successfully deal with the disadvantages of transparent materials which are isotropic. Experimental studies have shown newly developed transparent nonhomogeneous material properties close to real rocks, for the study of internal crack of rock which is no doubt highly beneficial. Due to fine brittle and transparency of the material, the internal crack growth can be clearly seen. Then the crack extension of the materials containing two preexisting flaws is investigated under uniaxial compression, with changing rock bridge angles, and rock bridge area is defined as shown in Figure 1; different modes of crack coalescence are observed in the $3 \mathrm{D}$ preexisting flaws specimens. Another main purpose of the paper is to predict the peak strength of transparent rock-like material containing preexisting flaws.

\section{Sample Preparation and Experimental Technique}

The discussion of the sample preparation and experimental technical contains three sections. The first section is the preparation of transparent casting resin modeling material; the second part is design of preexisting flaws in the samples; the third section is about the testing apparatus.

\subsection{Preparation of Transparent Casting Resin Modeling Mate-} rial Specimen. In the experiment, a new unsaturated resin is used to make specimens; sixty transparent rock-like parallelepiped samples are prepared and with cross section dimensions of $50 \mathrm{~mm} \times 50 \mathrm{~mm}$ and a height of $100 \mathrm{~mm}$ are used. The mica sheet is fixed inside the mould through fine cotton according the needed angle. The precise calculation ratio of liquid resin is poured into the mould mica sheet fixed. Some aggregates with different particle sizes are randomly embedded inside the transparent resin material in the process of casting resin material modeling. At room temperature for 24 hours, the specimens are taken out from the mould. After repeatedly baking in the oven for 3 to 5 times, with each baking time about 30 minutes, the specimens are freezing to $-30^{\circ} \mathrm{C}$, and then this material is perfectly brittle, deforms without barreling, and has linear stress-strain behavior up to 


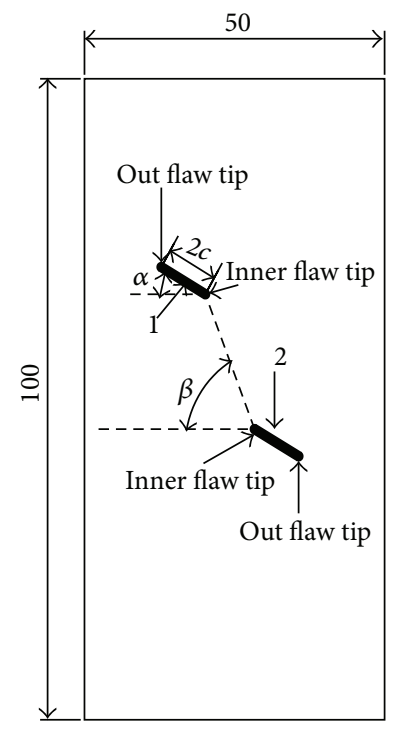

FIGURE 2: A specimen containing two preexisting flaws: the inclination is $\alpha$, the rock bridge angle is $\beta$, the length of the preexisting flaw is $2 c$, and the location of inner and outer flaw tips is defined.

its burst-like fracture. The mechanical properties evaluated during the tests are as follows: Young's modulus $E=7.553 \mathrm{GPa}$; uniaxial compressive strength $\sigma_{c}=93.488 \mathrm{MPa}$; fracture toughness $K_{I C}=0.6 \mathrm{MPa} \cdot \mathrm{m}^{1 / 2}$.

2.2. Design of Preexisting Flaws. A thin mica film (the thickness of $0.1 \mathrm{~mm}$ ) is used to model internal preexisting flaw during casting and be hold in the mould by cotton threads; it can represent a native open fracture of the rocks better for smaller stiffness than copper. The sizes of elliptical preexisting flaw are long axis $2 c$ of $12 \mathrm{~mm}$ and short axis $2 b$ of $8 \mathrm{~mm}$. The positions and orientations of the slots are predetermined to give the inclination of the cracks $\left(\alpha=30^{\circ}\right)$ and different rock bridge angle $(\beta)$, which is the relative inclination between the cracks. For the sake of later discussions, the flaws are labeled as 1,2 . Three different bridge angles are used in the experiment, which are $60^{\circ}, 85^{\circ}$, and $110^{\circ}$, as well as integrated species. Therefore, we can investigate the cracks coalescence along different rock bridge angles, as illustrated in Figure 2.

2.3. Testing Apparatus. The uniaxial compression test is carried out with RMT-150B multifunction automatic rigid rock servo material testing machine (Figure 3). Displacement control mode is adopted as the load method in this experiment. The specimens are loaded to fail at a minimum loading speed of $0.01 \mathrm{~mm} / \mathrm{s}$. The loading system records the values of load, displacement, and other parameters and draws the curve of load-displacement instantaneously. A video camera is connected to the microscope and all the images are transferred to a computer instantaneously, so that the process of crack evolution can be analyzed conveniently after testing.

\section{Results and Analysis}

Three types of models containing different rock bridge angles are tested to investigate the development of 3D fracture patterns. The following three sections depict the crack initiation, propagation, and coalescence of transparent resin materials with preexisting $3 \mathrm{D}$ cracks. The first section is general experimental observation; the second section is different model of crack coalescence for specimens containing different rock bridge angles; the third one is peak strength of $3 \mathrm{D}$ preexisting flaws specimens.

3.1. General Experimental Observation. Specimen with double preexisting flaws is experienced process of pressure elastic deformation, crack expansion, brittle failure, and residual strength on the whole. The coalescence of the specimen has much to do with the rock bridge angles.

Now the crack propagation process of specimen rock bridge angle $85^{\circ}$ is described in detail. According to the loading record and images obtained in the loading process, first stage is pressure dense phase and then the elastic deformation; when the stress reaches about $50 \%$ of the peak strength, the crack initiation appears first as a sudden at the inner tips of preexisting crack 1 in the form of leaping and is about half the length of the prefabricated crack axis; the typical pattern of wing crack is shown in Figure 4(a). The wrapping wing cracks then start to curve around the preexisting flaw boundary. When the stress reaches about $60 \%$ of the peak strength, the crack emerges from the tips of preexisting flaw 2 as a sudden, and the length is roughly the same as the length of axis. With loading increasing, the wing crack emerges from lower tip of preexisting flaw 1 and the upper tip of preexisting flaw 2 and grows in a stable way; later, different from the results of $2 \mathrm{D}$ crack growing, antiwing wrapping crack (its growth direction is opposite to the wing wrapping crack) is induced from preexisting flaw 2 , but the growing length is limited, as long as one-third of length of the short axis. At the same time, the wing cracks, respectively, from the upper tip of preexisting flaw 2 and lower tips of preexisting flaw 1 are growing towards each other but not coalescence. When the stress reaches about 70\% of the peak strength, a tiny type tension crack turns up in the middle part of rock bridge area; ultimately the growing of the secondary crack and the propagation of wing cracks lead to the coalescence of crack induced by the preexisting flaws. When the stress reaches about $75 \%$ of the peak strength, cracks begin to grow from the upper tip of preexisting flaw 1 . When the stress reaches about $90 \%$ of the peak strength, cracks come up in the no fissure zone and are quickly growing connecting with the cracks induced by the preexisting flaws. When the stress falls to about $20 \%$ of the peak strength, the effective bearing load area between particles is gradually reduced, and the specimen eventually damages, as shown in Figures $4(a)$ and $4\left(a^{\prime}\right)$.

The earlier stage of crack evolution of specimens with rock bridge angle $110^{\circ}$ has little difference from the one with rock bridge angle $85^{\circ}$. The wrapping wing cracks all come up from the inner tips of the preexisting flaws. The difference is that no secondary cracks are produced in the area of rock bridge during the process of crack growing, but the eventual 


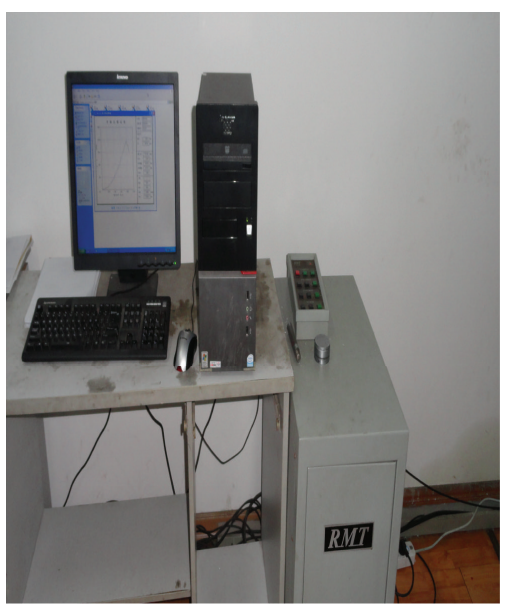

(a)

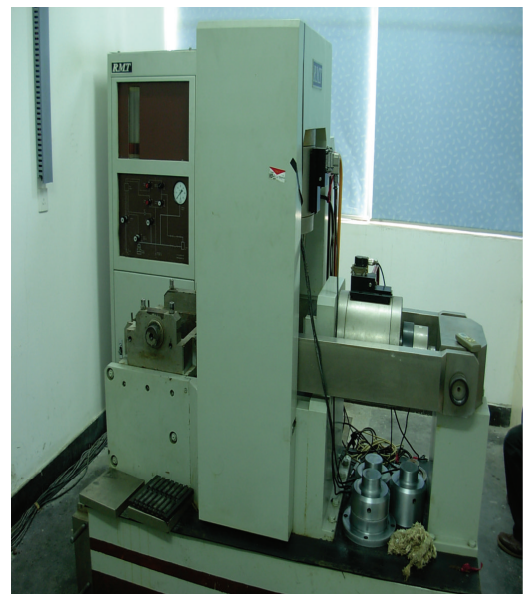

(b)

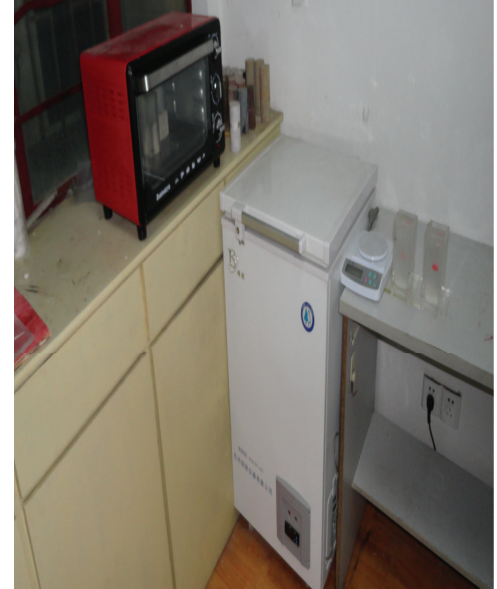

(c)

FIGURE 3: Test equipment: (a) data logger of RMT-150B multifunction automatic rigid rock servo material testing machine, (b) loading system of RMT-150B multifunction automatic rigid rock servo material testing machine, and (c) oven, which is used to test sample, make its curing as soon as possible, and increase its brittleness.

fracture is caused by wing cracks growing. That is to say, changing rock bridge angles will produce different mode of crack coalescence. As shown in Figures $4(\mathrm{~b})$ and $4\left(\mathrm{~b}^{\prime}\right)$, when loading is going on, the wing cracks start to curve towards the direction of loading, and wing crack plays a vital role in rock fracture.

The early stage of crack extension mode with bridge angle $60^{\circ}$ resembles rock bridge angles $85^{\circ}$ and $110^{\circ}$ of the specimens; wing crack emerges from the inner and outer tips of crack 1 and crack 2 long axis one after another. When the stress reaches about $70 \%$ of the peak strength, secondary cracks emerge from the inner tips of crack 1 and crack 2, respectively. With loading increasing, when the stress reaches about $70 \%$ of the peak strength, cracks are growing quickly and begin coalescence in rock bridge area. Eventually they damage and form a shear failure surface, as shown in Figures $4(c)$ and $4\left(c^{\prime}\right)$.

In general, most cracks initiation appeared first at the inner tips of the preexisting flaws; then growth follows at the outer tips of the preexisting flaws, but some cracks initiation occurs in the reverse order, growth at the inner tips followed by cracks initiated at the outer tips. The growth of cracks at the outer tips is faster than that observed at inner tips. The types of cracking in rock bridge area can appear as either shear, tensile, or mix of both modes of crack coalescence. Shear cracks initiate in two different directions: coplanar or quasicoplanar and oblique to the flaw [43]. A detailed discussion will be present in the next section.

\section{The Modes of Crack Coalescence in Rock Bridge Area}

In 2D modes, Wong and Chau [46] concluded that there were three modes of coalescence in rock bridge area. Patterns of crack coalescence of sandstone-like material containing two parallel inclined frictional cracks under uniaxial compression load are shown in Figure 5. The influence roles of the possible orientations of cracks included the values of inclination of preexisting cracks $\alpha$, bridge angle $\beta$, and the frictional coefficient $\mu$ on the surfaces of the two preexisting cracks. When crack coalescence occurs, three main types of cracking can be identified in the rock bridge area: wing cracks, which are tensile in nature; secondary cracks, which are mainly shear in nature and are normally parallel to the preexisting cracks; mixed shear/tensile crack coalescence. In all, three main modes are as follows: S-mode (shear crack coalescence), Mmode (mixed shear/tensile crack coalescence), and W-mode (wing tensile crack coalescence), as can be seen in Figure 5. According to the loading record, our interest is placed on the coalescence pattern in the rock bridge area. When the bridge angle is $85^{\circ}$ and when the stress reaches about $70 \%$ of the peak strength, a tiny secondary crack turns up in the middle part of rock bridge area; ultimately the growing of the secondary crack and the propagation of wing cracks lead to the coalescence of crack induced by the preexisting flaws. As can be seen in Figures 4(a) and 6(a), contrasting with the modes of $2 \mathrm{D}$ crack coalescence concluded by Wong, when $\alpha=$ $30^{\circ}, \beta=85^{\circ}$, the observations are resemblance as the situation shown in Figure 5(b). And the mode is M-mode (mixed shear and tensile crack coalescence). When the rock bridge angle is $110^{\circ}$, under uniaxial compression load, wing cracks initiate and grow from tips of preexisting cracks. Wing cracks from the inner tip of crack 1 propagate downward to the outer tip of crack 2; at the same time, wing cracks from outer tip of crack 2 propagate upward to the inner tip of crack 1 .

However, the specimens failed by axial splitting rather than localized coalescence failure. As shown in Figures 4(b) and 6(b), comparison with the coalescence mode of 2D crack induced which is proposed by Wong, seen in Figure 5(f), this crack coalescence mode is $\mathrm{W}$-mode (wing tensile crack coalescence). When the rock bridge angle is about $60^{\circ}$, wing cracks nucleation at both inner and outer tips of the 


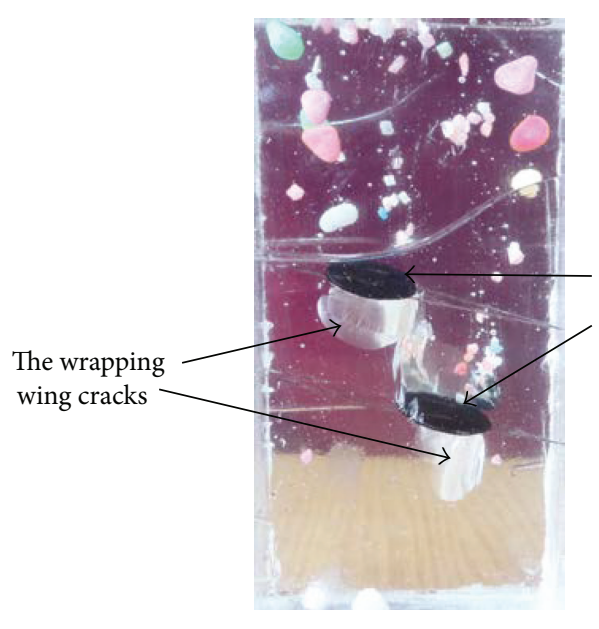

(a)

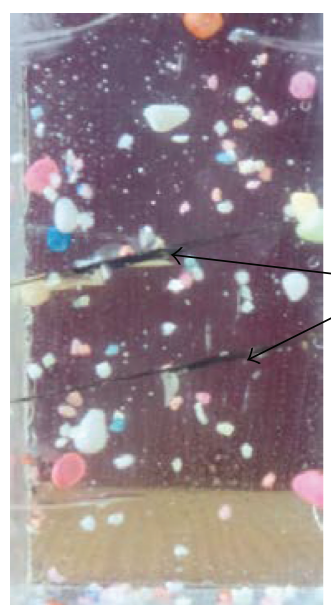

(b)

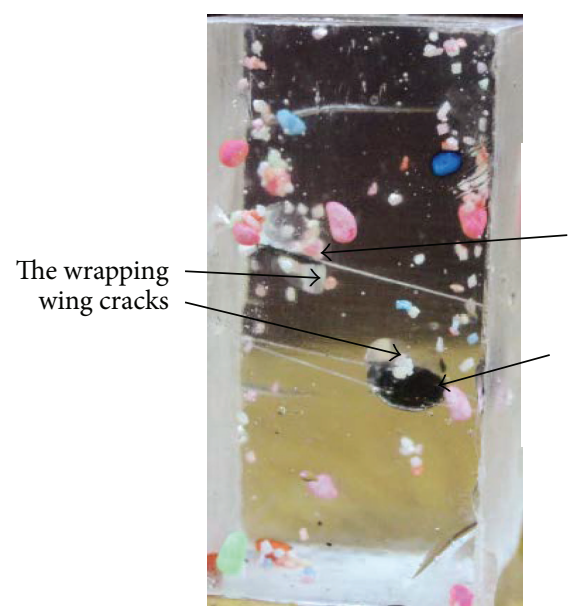

(c)

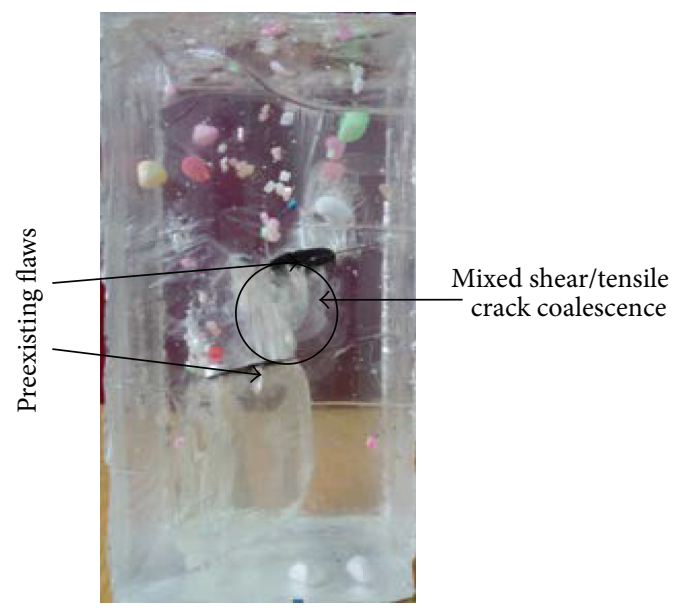

$\left(a^{\prime}\right)$

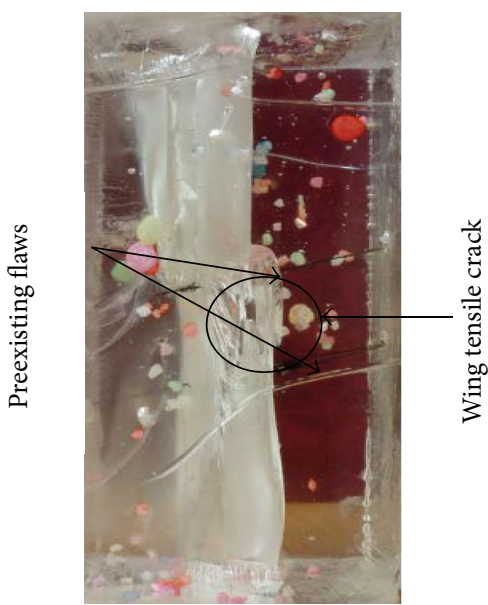

$\left(b^{\prime}\right)$

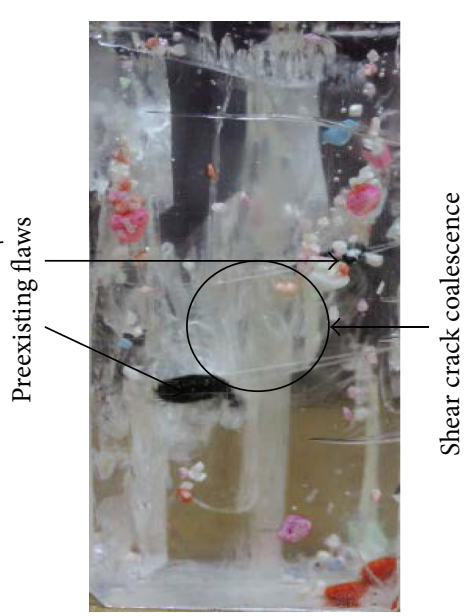

$\left(c^{\prime}\right)$

FIGURE 4: Modes of crack coalescence with different rock bridge angles: the inclination angle is about $30^{\circ}$; the frictional coefficient $\mu$ is about 0.577. (a) Showing the early stage of crack coalescence process under uniaxial compression when rock bridge angle is $85^{\circ}$, ( $\left.\mathrm{a}^{\prime}\right)$ showing the failure of the specimen under uniaxial compression when rock bridge angle is $85^{\circ}$; (b) showing the early stage of crack coalescence process under uniaxial compression when rock bridge angle is $110^{\circ},\left(\mathrm{b}^{\prime}\right)$ showing the failure of the specimen under uniaxial compression when rock bridge angle is $110^{\circ}$; (c) showing the early stage of crack coalescence process under uniaxial compression when rock bridge angle is $60^{\circ}$, $\left(c^{\prime}\right)$ showing the failure of the specimen under uniaxial compression when rock bridge angle is $60^{\circ}$. 


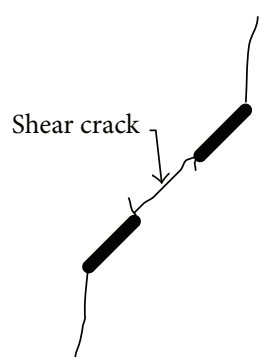

(a)

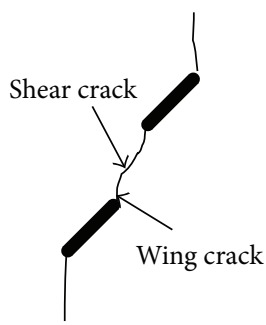

(b)

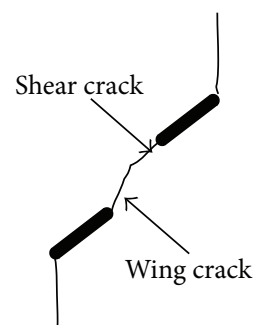

(c)

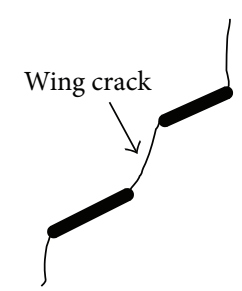

(d)

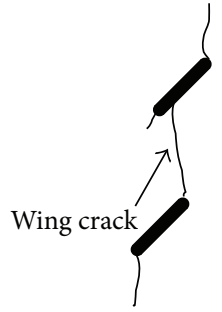

(e)

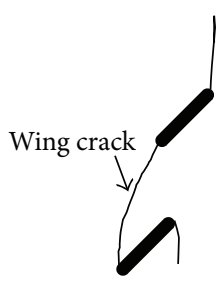

(f)

Figure 5: Six different patterns of crack coalescence were observed in the 2-flaw specimens. The notion of S, M, and W indicated the shear mode crack coalescence, mixed (shear/tensile) mode crack coalescence, and wing tensile mode crack coalescence (after Wong and Chau [46]).
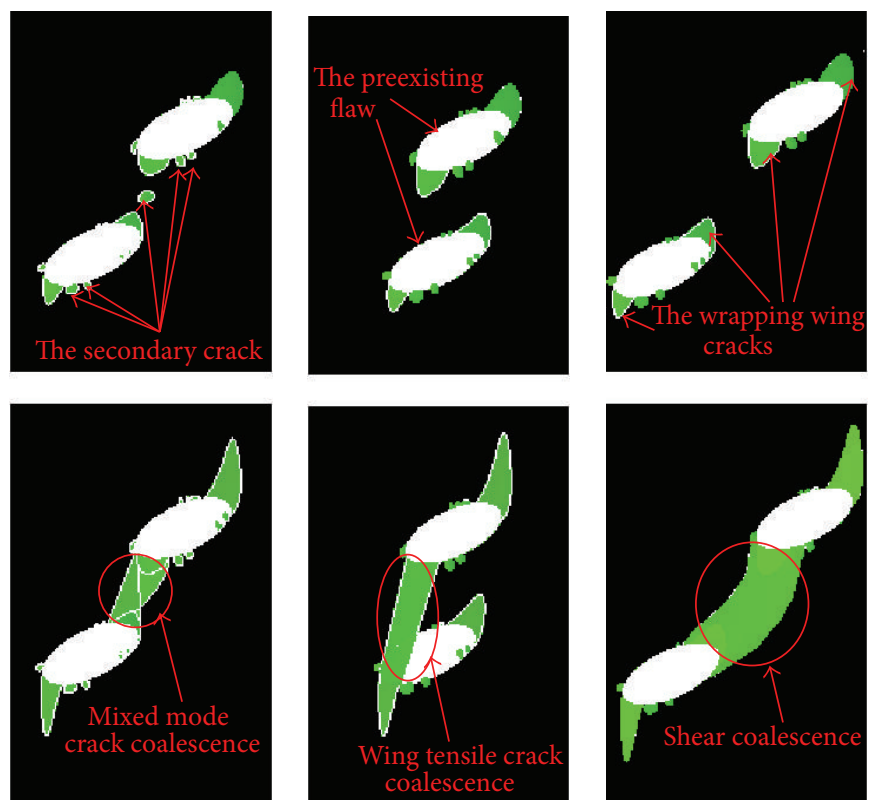

(a) $\alpha=30^{\circ}, \beta=85^{\circ}$

(b) $\alpha=30^{\circ}, \beta=110^{\circ}$

(c) $\alpha=30^{\circ}, \beta=60^{\circ}$

FIGURE 6: Three different patterns of 3D crack coalescence are observed in the tests.

preexisting crack normally occurs first, but before the wing cracks propagate further, secondary shear cracks nucleate from both kinks at inner tips. The secondary cracks nucleate from both kinks at tips. The propagation of these secondary cracks leads to shear coalescence in the rock bridge area while wing cracks spread to the edges of the specimen, as shown in Figures 4(c) and 6(c), and shear failure surface is formed eventually. This kind of coalescence is mainly induced by a high shear stress concentration in the bridge area. Our observations suggest that whenever the two preexisting main cracks are in alignment, the shear interactions between the preexisting cracks become dominant. In contrast with the coalescence mode of $2 \mathrm{D}$ crack induced which is proposed by Wong, seen in Figures 4(c) and 6(c), this crack coalescence 
mode is S-mode (shear crack coalescence), but there are some differences that the dominant induced role is shear stress, but the effect of tensile cannot be neglected.

\section{Peak Strength of Specimen with Flaws}

Peak strength prediction of rock containing preexisting flaws is discussed in this section. The mode raised by Ashby and Hallam [47] is employed. Ashby and Hallam derived the following approximate for wing cracks growing, which nucleated from a preexisting inclined crack of length $2 c$ when the specimen was subject to uniaxial compression strength $\sigma_{1}$ :

$$
\begin{aligned}
& \frac{K_{I}}{\sigma_{1} \sqrt{\pi c}} \\
& =\frac{(\sin 2 \psi-\mu+\mu \cos 2 \psi)}{(1+L)^{3 / 2}}\left[0.23 L+\frac{1}{\sqrt{3}(1+L)^{1 / 2}}\right] \\
& \quad+\left[\frac{2 \varepsilon_{0}(L+\cos \psi)}{\pi}\right]^{1 / 2},
\end{aligned}
$$

where $\sigma_{1}$ is the uniaxial compression strength, $\psi$ is the angle measured from the $\sigma_{1}$-direction along the main surface of the flaw $\left(\psi=90^{\circ}-\alpha\right), 2 c$ is the length of the preexisting flaw, and the flaw density $\varepsilon_{0}$ is defined as $N c^{2} / A(N$ is the number of flaw per area $A$ ). Although strictly speaking (1) is for the case of multiple initial flaws, it was found that it also can be employed for the specimen containing two flaws. Thus, the peak uniaxial compressive strength $\sigma_{1}{ }^{\max }$ of a flawed specimen can be estimated by Wong and Chau [46]:

$$
\begin{gathered}
\sigma_{1}^{\max }=\frac{K_{I C}}{\sqrt{\pi c}}\left\{\frac { [ \operatorname { s i n } 2 \psi - \mu + \mu \operatorname { c o s } 2 \psi ] } { ( 1 + L _ { c r } ) ^ { 3 / 2 } } \left[0.23 L_{c r}\right.\right. \\
\left.\left.+\frac{1}{\sqrt{3}\left(1+L_{c r}\right)^{1 / 2}}\right]+\left[\frac{2 e_{0}\left(L_{c r}+\cos \psi\right)}{\pi}\right]^{1 / 2}\right\}^{-1},
\end{gathered}
$$

where $K_{I C}$ is the fracture toughness (in this paper $K_{I C}=0.6 \mathrm{MPa} \cdot \mathrm{m}^{1 / 2}$ for our modeling material), $L_{c r}=$ $l_{\max } / c\left(l_{\max }=2 b \sin \beta\right.$ is the maximum possible value for length of the coalesced wing cracks, and $2 b$ is the distance between the two flaws), and $\mu$ is the frictional coefficient along the main shear crack; the orientation of the shear crack for which the nucleation of the wing crack is most favorable is given by $2 \psi=\tan ^{-1}(1 / \mu)$.

In this paper, the initial flaw density of specimen containing two flaws is $e_{0}=0.015\left(\varepsilon_{0}=N c^{2} / A\right.$; note that $N=2$, $A=0.05 \mathrm{~m} \times 0.10 \mathrm{~m}$, and $c=0.004 \mathrm{~m})$. Predictions of the normalized peak strength $\left(\sigma_{1}{ }^{\max } \sqrt{\pi c} / K_{I C}\right)$ by using (2) are

\begin{tabular}{|c|c|c|c|c|}
\hline \multirow{2}{*}{$\beta\left(^{\circ}\right)$} & \multicolumn{2}{|c|}{ Peak strength } & \multirow{2}{*}{$\varepsilon / 10^{-3}$} & \multirow{2}{*}{$E / G P a$} \\
\hline & Experimental & Theoretical & & \\
\hline Complete specimen & 21.46 & - & 16.08 & 6.15 \\
\hline 60 & 13.13 & 10.09 & 15.12 & 5.33 \\
\hline 85 & 12.86 & 16.51 & 14.04 & 5.15 \\
\hline 110 & 12.71 & 13.68 & 14.65 & 5.21 \\
\hline
\end{tabular}
listed in Table 1; furthermore the relationship between stress and strain of experimental results with different rock bridge
TABLE 1: Mechanical parameters of specimens with preexisting cracks of different bridge angles.

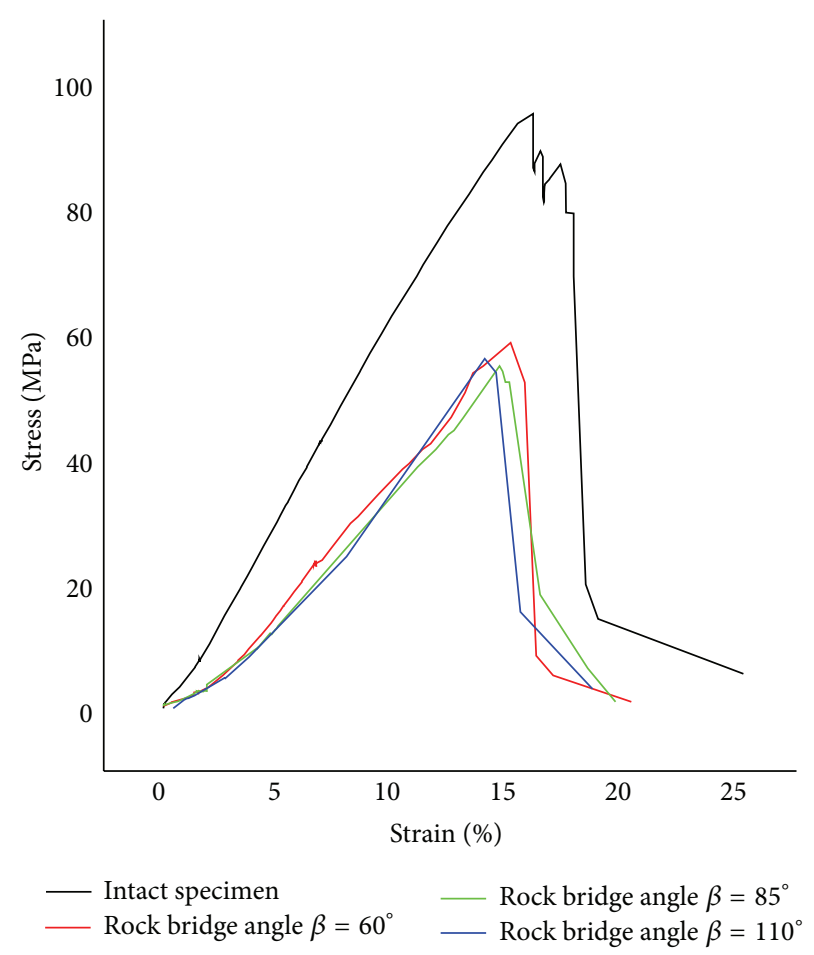

FIGURE 7: Stress and strain curves of samples with preexisting cracks of different bridge angles.

angles is compared (see in Figure 7). As given in (1), the former part of the formula,

$$
\begin{aligned}
& \frac{K_{I}}{\sigma_{1} \sqrt{\pi c}} \\
& \quad=\frac{(\sin 2 \psi-\mu+\mu \cos 2 \psi)}{(1+L)^{3 / 2}}\left[0.23 L+\frac{1}{\sqrt{3}(1+L)^{1 / 2}}\right] .
\end{aligned}
$$

Equation (3) was derived by Ashby and Hallam, which is an approximate expression for mode 1 stress intensity factor $K_{I}$ at the tip of the wing cracks, and the wing cracks nucleate from a preexisting inclined crack of length $2 c$ when the solid is subject to uniaxial compression strength $\sigma_{1}$.

If peak strength is to be predicted, crack interaction and coalescence must be incorporated into the analysis. Using beam theory, the following $K_{I}$ is due to crack interactions 
using beam theory, as can be seen from the later part of (2), and written as follows:

$$
\frac{K_{I}}{\sigma_{1} \sqrt{\pi c}}=\left\{\frac{2 e_{0}(L+\cos \psi)}{\pi}\right\}^{1 / 2} .
$$

Combining (3) and (4) gives the total stress intensity factor $K_{I}$ for the wing cracks with crack interaction. Equation (3) completes the elastic theory for cracks. But, as known, rock materials can become plastic if the compressive stress is large enough. When a beam of thickness $t$ and depth $b$ is subjected to an axial stress $\sigma_{1}$ and a bending moment $m$, it starts to yield when the maximum surface stress reaches the yield strength. Hence, an additional contribution to stress intensity can be written as (4). But as shown in Figure 7, the transparent resin material undergoes elastic deformation dominantly; it suffers axial compression load but no significant bending. In other words, stress-strain curves are typical of brittle behavior: the nonlinear strain before peak strength is fairly small, and resistance drops dramatically afterwards. So the influence of beam is negligible, and the equation which can be applied in the study is (3). However, some modification has been made about the equation; that is, when $\alpha<45^{\circ},|\cos 2 \psi|$ should be applied. The experimental observations and theoretical results of peak strength of specimens are shown in Table 1.

The prediction by using the Ashby-Hallam model [46], which is description in the previous section, is presented here for comparison, as shown in Table 1; it is clear to see that the predicted theoretical peak strength agrees well with the experimental observation, but some deviations still exist in the modified model. For example, the intensity tendency does not perfectly agree with the result of the experiment. Furthermore, the Ashby-Hallam model should not be applied without modification when the inclination of preexisting flaws $\alpha<45^{\circ}$ and the modification to be made requires more detailed analysis in the future.

\section{Conclusion}

In this paper, experimental results on the mechanism of $3 \mathrm{D}$ crack propagation and coalescence as well as the peak strength of transparent rock-like material containing preexisting flaws under uniaxial compression are presented. The specimens used in this study are made of frozen transparent resin material with different rock bridge angles; the following is found:

(i) It can be observed that coalescence in 3D flaws with different rock bridge angles can be identified as the shear mode, the mixed mode (tensile mode and shear mode), and wing tensile mode. When the inclination angle $\alpha=30^{\circ}$ and frictional coefficient $\mu=0.57$, the coalescence mode is dominated by different rock bridge angles. When $\beta=60^{\circ}$, shear mode coalescence occurs; when $\beta=85^{\circ}$, mixed mode coalescence occurs; when $\beta=110^{\circ}$, wing tensile mode coalescence occurs. Nevertheless, more 3D experimental and theoretical studies need to be carried out.

(ii) The existence of flaws greatly reduces the compression strength of the specimen, and the cracks existing make the peak strengths reduced. The uniaxial peak strength prediction of 3D cracks by Ashby-Hallam [46] compares well with the experimental result. And there is some modification of the mode which has been made. Nevertheless, further modification should be done to give a better prediction of peak strength.

\section{Conflict of Interests}

The authors declare that there is no conflict of interests regarding the publication of this paper.

\section{Acknowledgments}

The authors are grateful for the support of this work by the Natural Science Foundation of China (nos. 51404095, 51379065, and 41272329), the Chinese National Key Fundamental Research 973 Programme (2011CB013504), Colleges and Universities in Henan Province, the Construction of Deep Mine Open and Key Laboratory Open Fund (2013KF06), the Education Department of Henan Province Science and Technology Research Projects (13B560040), and Scientific Research Foundation of Henan Polytechnic University, Dr. (B2011-105).

\section{References}

[1] Y. Ichikawa, K. Kawamura, K. Uesugi, Y.-S. Seo, and N. Fujii, "Micro-and macrobehavior of granitic rock: observations and viscoelastic homogenization analysis," Computer Methods in Applied Mechanics and Engineering, vol. 191, no. 1-2, pp. 47-72, 2001.

[2] H. Haeri, K. Shahriar, M. F. Marji, and P. Moarefvand, "Cracks coalescence mechanism and cracks propagation paths in rocklike specimens containing pre-existing random cracks under compression," Journal of Central South University, vol. 21, no. 6, pp. 2404-2414, 2014.

[3] A. Bobet, "The initiation of secondary cracks in compression," Engineering Fracture Mechanics, vol. 66, no. 2, pp. 187-219, 2000.

[4] R. H. C. Wong, K. T. Chau, C. A. Tang, and P. Lin, "Analysis of crack coalescence in rock-like materials containing three flaws-part I: experimental approach," International Journal of Rock Mechanics and Mining Sciences, vol. 38, no. 7, pp. 909-924, 2001.

[5] E. Sahouryeh, A. V. Dyskin, and L. N. Germanovich, "Crack growth under biaxial compression," Engineering Fracture Mechanics, vol. 69, no. 18, pp. 2187-2198, 2002.

[6] Y.-P. Li, L.-Z. Chen, and Y.-H. Wang, "Experimental research on pre-cracked marble under compression," International Journal of Solids and Structures, vol. 42, no. 9-10, pp. 2505-2516, 2005.

[7] L. N. Y. Wong and H. H. Einstein, "Crack coalescence in molded gypsum and Carrara marble: part 1. Macroscopic observations and interpretation," Rock Mechanics and Rock Engineering, vol. 42, no. 3, pp. 475-511, 2009.

[8] L. N. Y. Wong and H. H. Einstein, "Crack coalescence in molded gypsum and carrara marble: part 2-Microscopic observations and interpretation," Rock Mechanics and Rock Engineering, vol. 42, no. 3, pp. 513-545, 2009. 
[9] C. H. Park and A. Bobet, "Crack coalescence in specimens with open and closed flaws: a comparison," International Journal of Rock Mechanics and Mining Sciences, vol. 46, no. 5, pp. 819-829, 2009.

[10] T. Y. Ko, H. H. Einstein, and J. Kemeny, "Crack coalescence in brittle material under cyclic loading," in Proceedings of the 41st US Symposium on Rock Mechanics, ARMA-06-930, Golden, Colo, USA, June 2006.

[11] C. H. Park and A. Bobet, "Crack initiation, propagation and coalescence from frictional flaws in uniaxial compression," Engineering Fracture Mechanics, vol. 77, no. 14, pp. 2727-2748, 2010.

[12] C.-a. Tang and Y.-f. Yang, "Crack branching mechanism of rocklike quasi-brittle materials under dynamic stress," Journal of Central South University, vol. 19, no. 11, pp. 3273-3284, 2012.

[13] H. Li and L. N. Y. Wong, "Influence of flaw inclination angle and loading condition on crack initiation and propagation," International Journal of Solids and Structures, vol. 49, no. 18, pp. 2482-2499, 2012.

[14] H. Haeri, K. Shahriar, M. F. Marji, and P. Moarefvand, "A coupled numerical-experimental study of the breakage process of brittle substances," Arabian Journal of Geosciences, vol. 8, no. 2, pp. 809-825, 2015.

[15] C. Nielsen and S. Nemat-Nasser, "Crack healing in cross-ply composites observed by dynamic mechanical analysis," Journal of the Mechanics and Physics of Solids, vol. 76, pp. 193-207, 2015.

[16] K. Horii, R. Yamada, and S. Harada, "Strength deterioration of nonfractal particle aggregates in simple shear flow," Langmuir, vol. 31, no. 29, pp. 7909-7918, 2015.

[17] R. H. C. Wong, C. A. Tang, K. T. Chau, and P. Lin, "Splitting failure in brittle rocks containing pre-existing flaws under uniaxial compression," Engineering Fracture Mechanics, vol. 69, no. 17, pp. 1853-1871, 2002.

[18] B. Shen, O. Stephansson, H. H. Einstein, and B. Ghahreman, "Coalescence of fractures under shear stresses in experiments," Journal of Geophysical Research, vol. 100, no. 4, pp. 5975-5990, 1995.

[19] H. Jiefan, C. Ganglin, Z. Yonghong, and W. Ren, "An experimental study of the strain field development prior to failure of a marble plate under compression," Tectonophysics, vol. 175, no. 1-3, pp. 269-284, 1990.

[20] J. T. Miller and H. H. Einstein, "Crack coalescence tests on granite," in Proceedings of the 42nd US Rock Mechanics Symposium (USRMS '08), ARMA-08-162, San Francisco, Calif, USA, June 2008.

[21] L. N. Y. Wong and H. H. Einstein, "Using high speed video imaging in the study of cracking processes in rock," Geotechnical Testing Journal, vol. 32, no. 2, pp. 164-180, 2009.

[22] S. Nemat-Nasser and H. Horii, "Compression-induced nonplanar crack extension with application to splitting, exfoliation, and rockburst," Journal of Geophysical Research, vol. 87, no. 8, pp. 6805-6821, 1982.

[23] S. Q. Yang, Y. H. Dai, L. J. Han, and Z. Q. Jin, "Experimental study on mechanical behavior of brittle marble samples containing different flaws under uniaxial compression," Engineering Fracture Mechanics, vol. 76, no. 12, pp. 1833-1845, 2009.

[24] R. J. Fowell and C. Xu, "The use of the cracked Brazilian disc geometry for rock fracture investigations," International Journal of Rock Mechanics and Mining Sciences and, vol. 31, no. 6, pp. 571-579, 1994.
[25] S. L. Crouch, "Analysis of stresses and displacements around underground excavations: an application of the displacement discontinuity method," University of Minnesota Geomechanics Report, University of Minnesota, Minneapolis, Minn, USA, 1967.

[26] E. Hoek and E. T. Brown, Underground Excavations in Rock, Institute of Mining and Metallurgy, London, UK, 1980.

[27] B. G. White, "Shear mechanism for mining-induced fractures applied to rock mechanics of coal mines," in Proceedings of the 21st International Conference on Ground Control in Mining, pp. 328-334, West Virginia University, Morgantown, WVa, USA, 1999.

[28] R. T. Ewy and N. G. W. Cook, "Deformation and fracture around cylindrical openings in rock-I. Observations and analysis of deformations," International Journal of Rock Mechanics and Mining Sciences \& Geomechanics Abstracts, vol. 27, no. 5, pp. 387-407, 1990.

[29] R. T. Ewy and N. G. W. Cook, "Deformation and fracture around cylindrical openings in rock-II. Initiation, growth and interaction of fractures," International Journal of Rock Mechanics and Mining Sciences and, vol. 27, no. 5, pp. 409-427, 1990.

[30] A. A. Griffith, "The phenomena of rupture and flow in solids," Philosophical Transactions of the Royal Society of London Series A, vol. 221, pp. 163-198, 1921.

[31] A. A. Griffith, "The theory of rupture," in Proceedings of the 1st International Congress for Applied Mechanics, pp. 55-63, Delft, The Netherlands, April 1924.

[32] R. L. Kranz, "Crack-crack and crack-pore interactions in stressed granite," International Journal of Rock Mechanics and Mining Sciences \& Geomechanics Abstracts, vol. 16, no. 1, pp. 3747, 1979.

[33] M. L. Batzle, G. Simmons, and R. W. Siegfried, "Microcrack closure in rocks under stress: direct observation," Journal of Geophysical Research, vol. 85, no. 12, pp. 7072-7090, 1980.

[34] A. V. Dyskin, R. J. Jewell, H. Joer, E. Sahouryeh, and K. B. Ustinov, "Experiments on 3-D crack growth in uniaxial compression," International Journal of Fracture, vol. 65, no. 4, pp. R77-R83, 1994.

[35] A. V. Dyskin, E. Sahouryeh, R. J. Jewell, H. Joer, and K. B. Ustinov, "Influence of shape and locations of initial 3-D cracks on their growth in uniaxial compression," Engineering Fracture Mechanics, vol. 70, no. 15, pp. 2115-2136, 2003.

[36] A. V. Dyskin, L. N. Germanovich, R. J. Jewell, H. Joer, J. S. Krasinski, and K. K. Lee, "Study of 3-D mechanisms of crack growth and interaction in uniaxial compression," ISRM News Journal, vol. 2, no. 1, pp. 17-20, 1994.

[37] A. Srivastava and S. Nemat-Nasser, "Overall dynamic properties of three-dimensional periodic elastic composites," The Royal Society of London-Series A: Proceedings, vol. 468, no. 2137, pp. 269-287, 2012.

[38] C. K. Teng, X. C. Yin, and S. Y. Li, "An experimental investigation on $3 \mathrm{D}$ fractures of non-penetrating crack in plane samples," Acta Oceanologica Sinica, vol. 30, no. 4, pp. 371-378, 1987 (Chinese).

[39] X. C. Yin, S. Y. Li, and H. Li, "Experimental study of interaction between two flanks of closed crack," Acta Geophysica Sinica, vol. 31, no. 3, pp. 307-314, 1988 (Chinese).

[40] R. H. C. Wong, M. L. Huang, M. R. Jiao, C. A. Tang, and W. Zhu, "The mechanisms of crack propagation from surface 3-D fracture under uniaxial compression," Key Engineering Materials, vol. 261, no. I, pp. 219-224, 2004. 
[41] R. H. C. Wong, Y. S. Guo, and L. Y. Li, "Anti-wing crack growth from surface flaw in real rock under uniaxial compression," in Fracture of Nano and Engineering Materials and Structures: Proceedings of the 16th European Conference of Fracture, Alexandroupolis, Greece, July 3-7, 2006, E. E. Gdoutos, Ed., pp. 825826, Springer, Amsterdam, The Netherlands, 2006.

[42] R. H. C. Wong, Y. S. Guo, and K. T. Chau, "The fracture mechanism of 3D surface fault with strain and acoustic emission measurement under axial compression," Key Engineering Materials, vol. 358, pp. 2360-3587, 2007.

[43] Y. S. Guo, R. H. C. Wong, W. S. Zhu, K. T. Chau, and S. Li, "Study on fracture pattern of open surface-flaw in gabbro," Chinese Journal of Rock Mechanics and Engineering, vol. 26, no. 3, pp. 525-531, 2007.

[44] L. Q. Liu, P. X. Liu, H. C. Wong, S. P. Ma, and Y. S. Guo, "Experimental investigation of three-dimensional propagation process from surface fault," Science in China, Series D: Earth Sciences, vol. 51, no. 10, pp. 1426-1435, 2008.

[45] Y. S. Guo, The study on experiment, theory and numerical simulation of fracture of three-dimensional flaws in brittle materials [Ph.D. thesis], Shandong University, Jinan, China, 2007.

[46] R. H. C. Wong and K. T. Chau, "Crack coalescence in a rock-like material containing two cracks," International Journal of Rock Mechanics and Mining Sciences, vol. 35, no. 2, pp. 147-164, 1998.

[47] M. F. Ashby and S. D. Hallam, "The failure of brittle solids containing small cracks under compressive stress states," Acta Metallurgica, vol. 34, no. 3, pp. 497-510, 1986. 

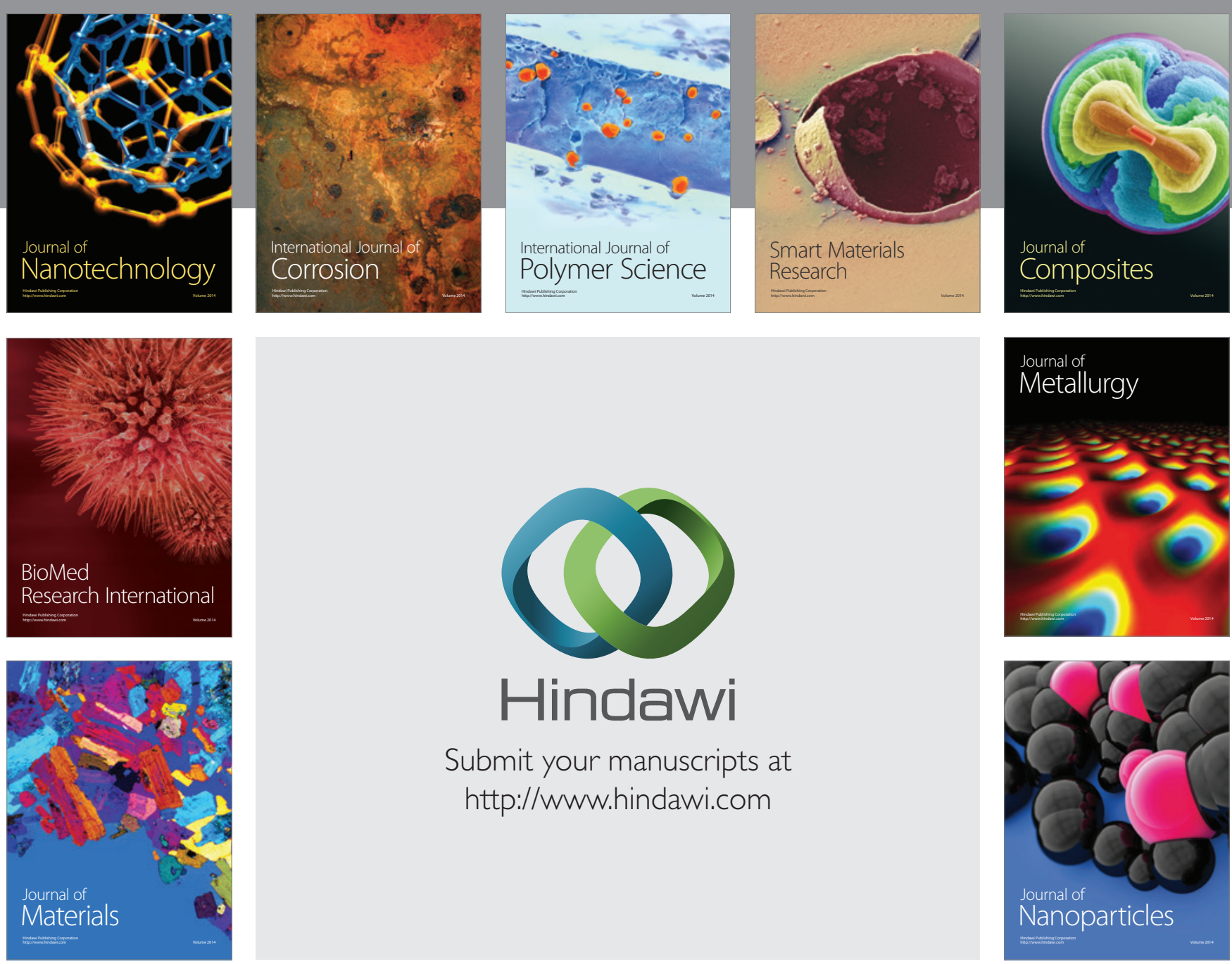

Submit your manuscripts at http://www.hindawi.com
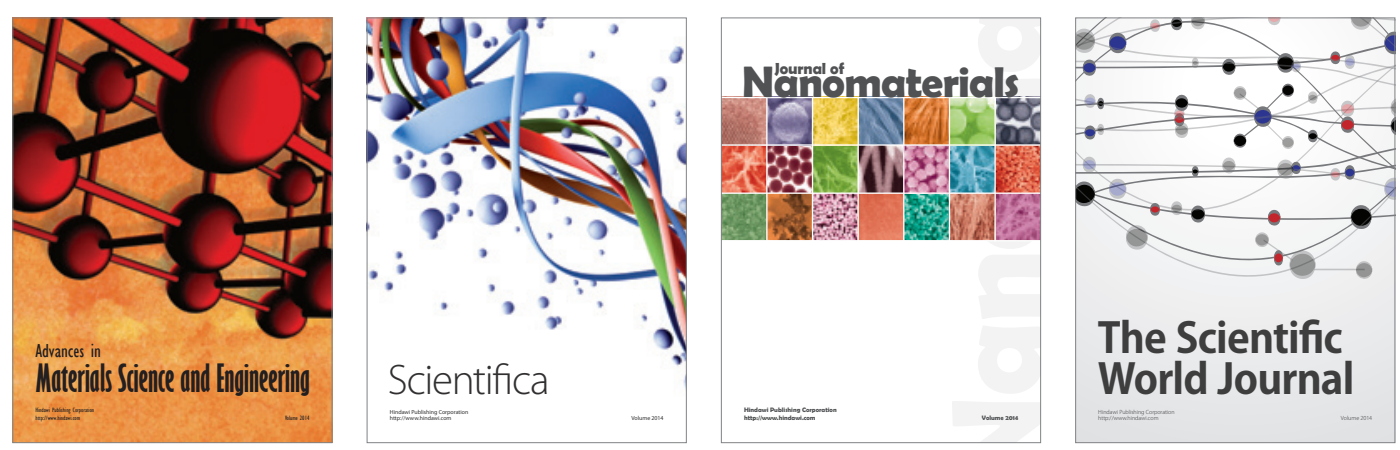

\section{The Scientific World Journal}
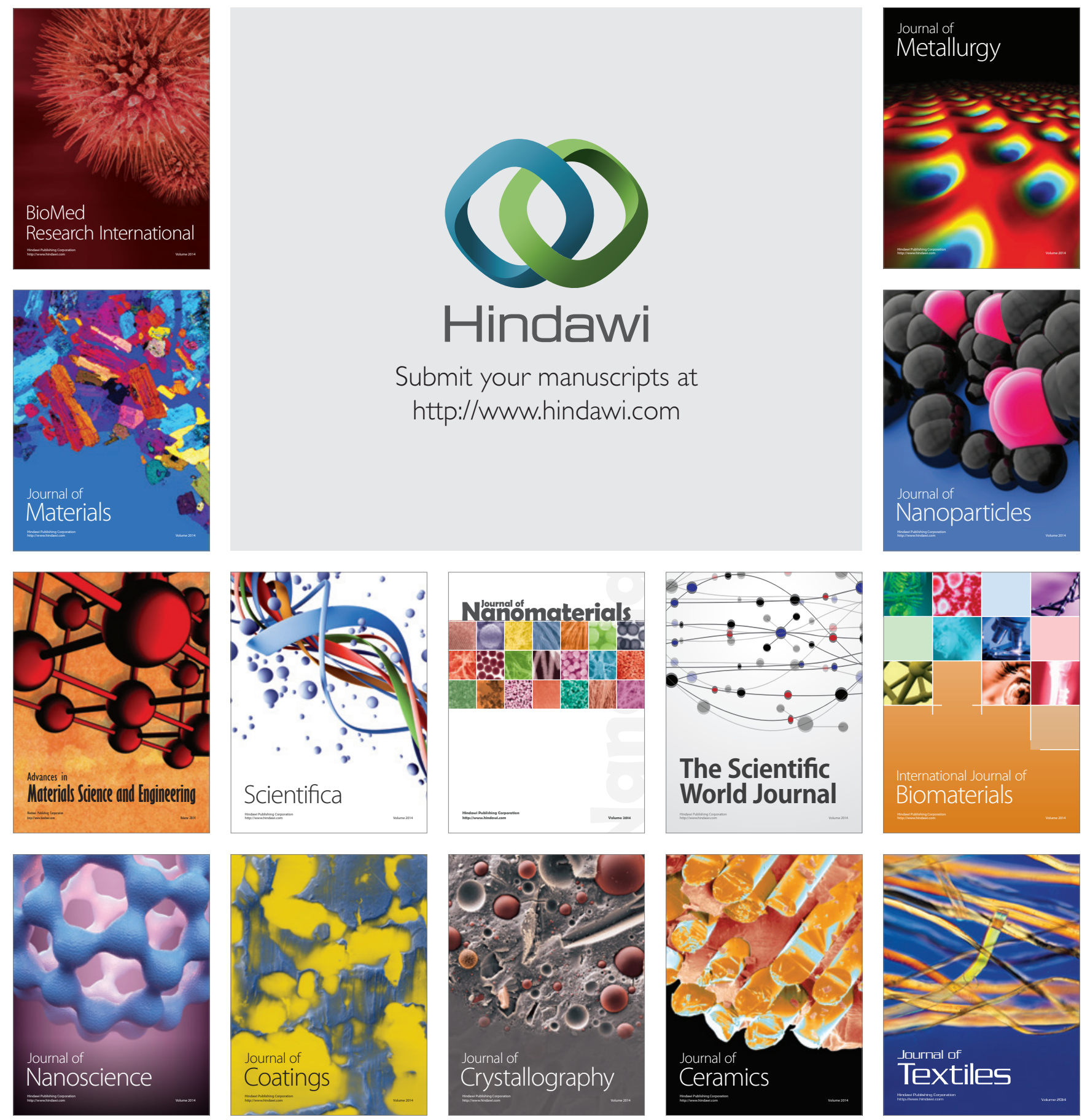